however, by the heavy crops in India and Argentina. Australia considerably increased her wheat area, as did also the United States and Canada; indeed, during the first year of the war the wheat area of the world was extended by more than I $8,000,000$ acres. In the later years of the war the difficulty was one of transport rather than of tota! supply; a great effort was therefore made after the close of rgr6 to increase food production in the United Kingdom. The methods and results have been discussed from time to time in these columns : the general result was a steady increase in production right up to $19 r 8$, the figures for the United Kingdom being in thousands :- -

\begin{tabular}{|c|c|c|c|c|c|c|}
\hline & & 1914 & 1915 & 1916 & 1917 & 5918 \\
\hline Wheat ... & quarters & 7,804 & 9,239 & 7,472 & 8,040 & I 1,643 \\
\hline Barley ... & 2 & 8,066 & 5,862 & 6,613 & 7,185 & 7,760 \\
\hline Oats & " & 20,664 & 22,308 & 21,334 & 26,021 & 31,196 \\
\hline Beans & , & I, 120 & 924 & 893 & 474 & 93 I \\
\hline Peas & ", & 374 & 300 & $26 \mathrm{I}$ & 278 & $44 \mathrm{I}$ \\
\hline Potatoes... & ons & 7,476 & 7,540 & 5,469 & 8,604 & 9,223 \\
\hline
\end{tabular}

This high production was obtained at a time when manures were scarce and implements difficult to repair, and when most of the skilled men were gone, their places being taken by old people, women, and children. But these substitutes worked with a will, and amply made up in enthusiasm what they lacked in skill. Even the high production of I9I8 was not the maximum possible, and had the conditions persisted, even higher results could have been obtained.

The last section of the book deals with postwar conditions. Serious fears had been entertained as to the food supplies of the world; fortunately, these have not been realised, and although food is undoubtedly scarce and will remain so there is no reason to fear famine, and in the main the people of Europe, though still suffering privation, are better fed than they were in 1918. It is difficult to say what the position is likely to be in the near future, but the redeeming feature is the rapidity with which agriculture has been restarted in the devastated areas of France and Belgium. Of the 4,000,000 acres damaged by the war, nearly a quarter were handed back to the cultivators before a year had elapsed. On the other hand, agriculturists in our own country are not producing so much as they did. The withdrawal of the women from the land and their replacement by men coincided with a considerable fall in production, which is distinctly unfortunate. A further fall is anticipated as a result of the shortened hours of labour.

Other countries, however, are in a worse preNO. 2637 , VOL. IO5] dicament. Russia, formerly one of the chief wheat-producing countries of the world, is unlikely to have any exportable surplus, and the position in Central Europe is still very obscure. Sir Henry Rew is not greatly perturbed, but thinks that if the social and political conditions of Europe became settled, its food production would rise to pre-war level in the course of two or three years. $\mathrm{He}$ is also quite hopeful about the position in this country. No student of British agriculture can ever give up hope of the future, and Sir Henry Rew is one of the leaders of the helpful band of optimists.

E. J. Russell.

\section{Differential Geometry.}

The Elementary Differential Geometry of Plane Curves. By R. H. Fowler. (Cambridge Tracts in Mathematics and Mathematical Physics. No. 2o.) Pp. viit I05. (Cambridge: At the University Press, I920.) Price 6s. net.

IFFERENTIAL geometry is a fascinating subject, because it gives us vivid and picturesque embodiments of theorems obtained by the combination of several branches of pure analysis, such as algebra, function-theory, and the infinitesimal calculus. It presents us with problems of all degrees of difficulty, from the comparatively simple theory of curvature and torsion to the provokingly difficult question of geodesics.

The present tract is just what its title indicates, except that there are a few digressions on twisted curves and on surfaces. The work has two conspicuous merits; in applying the differential calculus, the assumptions made are explicitly pointed out, and proper attention is paid to the determination of sign. The latter point is particularly important, not only because an error in sign is the one most frequently committed in computation, but also because, if a consistent determination of sign is not strictly adhered to, the formulx of analytical and even of pure geometry cease to have general validity. Even now our text-books, especially in analytical geometry, pay so little attention to this matter that a university teacher has to spend much valuable time on this topic with intermediate students, and too frequently finds, to his disgust, that even an honours student is not so careful as he should be in the matter of sign.

Mr. Fowler's chapters on tangents and normals, curvature, contact and envelopes, leave little, if anything, to be desired. The chapter on envelopes is the most thorough-going, and suggests a couple of remarks. The elimination of $\alpha$ from the equations $f(x, y, \alpha)=0, \partial f / \partial \alpha=0$ leads to a definite locus 
which may break up into a number of distinct, irreducible curves. How far any one of these curves should be considered to form a part of the envelope proper depends upon our definition of "envelope." For instance, in the author's example (p. 6r)-

$$
(y-\alpha)^{2}-x^{3}=0,
$$

the a-eliminant is $x^{3}=0$, which is a cusp-locus : Mr. Fowler refuses to regard this as an envelope, but if we regard the cusps as limiting forms of nodes, we may fairly regard $x=0$ as the limit of an envelope. However, this is a matter of slight importance, because each case that occurs can be treated independently.

On p. 60 we have the example-

$$
a^{2} f+(2 a+I) h=0,
$$

where the $a$-eliminant is $h(h-f)=0$, and neither $h=0$ nor $h-f=0$ is an envelope. If we put $(2 \alpha+\mathbf{I}) / \alpha^{2}=\beta$, the family of curves is $f+\beta h=0$, and the $\beta$-eliminant is $h=0$. It seems worth while to direct attention to this apparent discrepancy, because similar cases occur in problems of maxima and minima, etc. If, starting with $f+\beta h=0$, we replace $\beta$ by $(2 \alpha+\mathrm{r}) / \alpha^{2}$, we obtain, by variation of $\alpha$, the same pencil of curves; but, generally speaking, each curve occurs twice, and, as a rule, for different values of $\alpha$. If $\beta=-1$, $(\alpha+1)^{2}=0$, and the curve $f-h=0$ counts twice for the double value $\alpha=-1$, and hence $f-h=0$ occurs in the $\alpha$-eliminant, though it does not appear in the $\beta$-eliminant. Similar results, of a more complicated kind, occur if in $f+\beta h=0$ we put $\beta=\phi(\alpha) / \psi(\alpha)$, where $\phi(\alpha), \psi(\alpha)$ are any polynomials in $\alpha$.

In his last two chapters we think Mr. Fowler has rather lost his sense of proportion. In the eight pages devoted to the singular points of plane curves, scarcely anything more is attempted than a discussion of ordinary nodes and cusps; on the other hand, fourteen pages are filled with the theory of rectilinear and curvilinear asymptotes, and many of the results may fairly be said to be more interesting in function-theory than in geometry proper.

The author has conscientiously given references to the text-books which he has more or less followed in his exposition; but there is no bibliography of original papers, such as add greatly to the value of other tracts in this series. We hope that in future editions this want will be supplied; reference should at least be made to Puiseux, Weierstrass, Smith, and Halphen in connection with singular points.

No. 2637 , VOL. IO5]

\section{A Garden in the Dunes.}

Arcachon, Ville de Santé: Monographie Scientifique et Médicale. By Dr. F. Lalesque. Pp. viii +798 . (Paris: Masson et Cie, 19r9.) Price 25 francs net.

THIS handsome volume is mainly a justification of Arcachon as a health-resort, and it should appeal to those who feel the attractions of a life in France, and yet shrink from the crowd and cosmopolitan gaiety of the Mediterranean Riviera. The author is not content, however, with giving climatic temperature-charts, records of rainfall, and views of exercises on the shore and of yachting on the broad sea-basin. He has made a "regional survey" of his district, and the details of the natural history will provide matter of much interest to those who sojourn in the town. The modern "town" is a veritable garden city, especially developed in the last twenty years in accordance with Dr. Lalesque's scheme for $l a$ cure libre, and the separate villas provided in the ville d'hiver among the woods offer the patient the cheerful encouragements of family life in place of the more formal control of the sanatorium. The sand-dunes have been captured, as it were, and converted into shelters, while the fishing village on the open northern strand has been enlarged as a place for summer bathing.

Arcachon, indeed, began its career of usefulness when Francois Legallais, a retired sea-captain; imported from India to its desolate sand-hills the idea of the bungalow in I823. Dr. Lalesque gives us, in a few brief lines, a sketch of this rather captivating incident in human settlement and geography. His range of vision is wide. $\mathrm{He}$ interests us equally in the wind-worn grains of magnetite brought northward from the great fandeltas of the Adour system; in the "alios," a ferruginous conglomerate formed as an iron-pan in the subsoil, the permeability of which has now been triumphantly established; in the health of the oyster, an inoffensive creature, infected with typhoid germs entirely by the carelessness of man; and in the diatoms that flourish in the Lac de Cazeaux, to the actual benefit, it appears, of the water-supply of Arcachon. Dr. Lalesque in 1890 made an independent investigation of the irritating power on the human skin of the processionary caterpillar, the larva of Bombyx pityocampa, which inhabits the pine-trees of the coast, and he concludes that the hairs which cause urticaria are scattered from the nests of the insect by the wind. Even this affection seems trivial at Arcachon; we can imagine a visitor, temporarily inclined to irritation, being calmed by Dr. Lalesque's 